\title{
LETTER
}

\section{New tracheal tubes to prevent ventilator-associated pneumonia: where is the evidence?}

\author{
Saad Nseir $1,2 *$ \\ See related viewpoint by Zolfaghari and Wyncoll, http://ccforum.com/content/15/5/310
}

Zolfaghari and Wyncoll [1] propose that it may now be against good medical practice to continue to use a 'standard cuffed tube' given the weight of evidence supporting the use of newer tube designs to prevent ventilator-associated pneumonia (VAP).

There is strong evidence supporting the use of subglottic aspiration to prevent VAP [2]. However, other new tracheal tubes, such as polyurethane cuffed, silver-coated, or low-volume low-pressure tubes, could not be recommended to prevent VAP in routine practice. Although recent studies found polyurethane-cuffed tracheal tubes to be associated with significantly reduced VAP rate, major limitations of these studies preclude definitive conclusions; these limitations include the use of subglottic aspiration [3], before/after study design [4], and clinical criteria to define pneumonia $[4,5]$.

One large multicenter study found the use of silvercoated tracheal tubes to be associated with significant reduction in VAP rate [6]. However, limitations of this study should be taken into account, such as the significant difference in the proportion of patients with chronic obstructive pulmonary disease between the two groups, and the small rate of late-onset VAP.

Low-volume, low-pressure tracheal tubes were found to be associated with significantly reduced leakage of blue dye in a randomized controlled study performed in a single ICU [7]. Similarly, some in vitro studies suggested beneficial effects of conical shaped and guayule latex double-layered cuffs [8]. However, to date no randomized controlled study has evaluated the effect of these tubes on VAP prevention [9].

Therefore, further well designed studies are required before recommending the use of new tracheal tubes in every critically ill patient requiring mechanical ventilation for longer than 24 hours.

\section{Authors' response \\ Parjam S Zolfaghari and Duncan LA Wyncoll}

We thank Dr Nseir for his comments and his active involvement in innovations to reduce microaspiration leading to VAP. The main aim of our viewpoint article [1] was to highlight the pathophysiology of VAP and to encourage clinicians to question the viability of continued use of older PVC tubes. Clearly, reducing the burden of VAP requires a multifactorial approach as set out in our paper. The evidence base for some of these interventions is quite robust, that is, subglottic secretion drainage [2]. However, other interventions such as polyurethane and

*Correspondence: s-nseir@chru-lille.fr

Réanimation Médicale, Hôpital Calmette, CHRU, boulevard du Pr Leclercq, 59037 Lille cedex, France low-volume, low-pressure cuffed tubes have also shown promising results in in vitro and in limited in vivo studies $[4,10,11]$. We too would very much welcome further high quality randomised trials from those clinicians who still have equipoise, investigating the impact of such tubes on VAP prevention. However, assuming the correct pathogenesis of VAP and the properties of the new tubes with formation of better tracheal seal to reduce microaspiration and subglottic secretion drainage, we stand by our recommendations.

\section{Abbreviations}

VAP, ventilator-associated pneumonia.

Competing interests

Potential conflict of interest: Covidien (advisory board). 


\section{Author details}

IIntensive Care Unit, Calmette Hospital, University Hospital of Lille, boulevard du Pr Leclercq, 59037 Lille cedex, France. ${ }^{2}$ Medical Assessment Laboratory, EA 2694, Lille II University, 1 place de Verdun, 59045 Lille, France.

Published: 8 December 2011

\section{References}

1. Zolfaghari P, Wyncoll D: The tracheal tube: gateaway to ventilatorassociated pneumonia. Crit Care 2011, 15:310

2. Muscedere J, Rewa O, McKechnie K, Jiang X, Laporta D, Heyland DK: Subglottic secretion drainage for the prevention of ventilator-associated pneumonia: a systematic review and meta-analysis. Crit Care Med 2011, 39:1985-1991.

3. Lorente L, Lecuona M, Jiménez A, Mora ML, Sierra A: Influence of an endotracheal tube with polyurethane cuff and subglottic secretion drainage on pneumonia. Am J Respir Crit Care Med 2007, 176:1079-1083.

4. Miller MA, Arndt JL, Konkle MA, Chenoweth CE, Iwashyna TJ, Flaherty KR, Hyzy RC: A polyurethane cuffed endotracheal tube is associated with decreased rates of ventilator-associated pneumonia. J Crit Care 2011, 26:280-286.

5. Poelaert J, Depuydt P, De Wolf A, Van de Velde S, Herck I, Blot S: Polyurethane cuffed endotracheal tubes to prevent early postoperative pneumonia after cardiac surgery: a pilot study. J Thorac Cardiovasc Surg 2008, 135:771-776.

6. Kollef MH, Afessa B, Anzueto A, Veremakis C, Kerr KM, Margolis BD, Craven DE, Roberts PR, Arroliga AC, Hubmayr RD, Restrepo MI, Auger WR, Schinner R,
NASCENT Investigation Group: Silver-coated endotracheal tubes and incidence of ventilator-associated pneumonia: the NASCENT randomized trial. JAMA 2008, 300:805-813.

7. Lucangelo U, Zin WA, Antonaglia V, Petrucci L, Viviani M, Buscema G, Borelli M, Berlot G: Effect of positive expiratory pressure and type of tracheal cuff on the incidence of aspiration in mechanically ventilated patients in an intensive care unit. Crit Care Med 2008, 36:409-413.

8. Zanella A, Scaravilli V, Isgrò S, Milan M, Cressoni M, Patroniti N, Fumagalli R, Pesenti A: Fluid leakage across tracheal tube cuff, effect of different cuff material, shape, and positive expiratory pressure: a bench-top study. Intensive Care Med 2011, 37:343-347.

9. Nseir S, Zerimech F, Jaillette E, Artru F, Balduyck M: Microaspiration in intubated critically ill patients: diagnosis and prevention. Infect Disord Drug Targets 2011, 11:413-423.

10. Dullenkopf A, Gerber A, Weiss M: Fluid leakage past tracheal tube cuffs: evaluation of the new Microcuff endotracheal tube. Intensive Care Med 2003, 29:1849-1853.

11. Young PJ, Pakeerathan S, Blunt MC, Subramanya S: A low-volume, lowpressure tracheal tube cuff reduces pulmonary aspiration. Crit Care Med 2006, 34:632-639.

doi:10.1186/cc10557

Cite this article as: Nseir S: New tracheal tubes to prevent ventilatorassociated pneumonia: where is the evidence? Critical Care 2011, 15:459. 